\title{
Long-Term Medicaid Excess Payments from Alleged Price Manipulation of Generic Lorazepam
}

Boyang Bian, BPharm, MS; Elizabeth Gorevski, PharmD, MS; Christina M.L. Kelton, PhD; Jeff J. Guo, PhD; and Jill E. Martin Boone, PharmD

\begin{abstract}
BACKGROUND: Cost savings from the use of generic drugs versus brandname drugs are well known. Both private and public prescription drug plans encourage the use of generic drugs through a variety of mechanisms. The magnitude of cost savings for a given generic drug is dependent on the degree to which the generic market is competitive. Should the competitive structure become compromised, higher prices and reduced cost savings may result. An alleged conspiracy between Mylan Laboratories and its active-ingredient suppliers in 1997 was associated with an increase in seller concentration in the generic lorazepam market. The Federal Trade Commission (FTC) alleged that Mylan raised costs to consumers by $\$ 120$ million because of price increases for generic lorazepam from March through December 1998 and for generic clorazepate from January through December 1998. In November 2002, a settlement with Mylan was approved by the FTC, and a federal district court required Mylan to pay \$147 million, including \$28.2 million to state agencies including Medicaid.
\end{abstract}

OBJECTIVES: To (a) describe the seller concentration in the national Medicaid generic lorazepam market over a 19 -year period from January 1991 through December 2009, (b) estimate the excess payments for generic lorazepam by Medicaid between 1998 and 2009, and (c) investigate potentially increased utilization and prices of 2 substitute pharmaceuticals: branded lorazepam (Ativan) and generic alprazolam (another widely used intermediate-acting benzodiazepine).

METHODS: Using Medicaid State Drug Utilization Data from the Centers for Medicare \& Medicaid Services, we calculated the 4-firm concentration ratio $\left(\mathrm{CR}_{4}\right)$ and the Herfindahl-Hirschman Index $(\mathrm{HHI})$ for the Medicaid generic lorazepam market, along with pre-rebate reimbursement for pharmacy claims, number of claims (utilization), and average pre-rebate reimbursement per claim (average "price") for generic lorazepam, from 1991 through 2009. Medicaid's excess payments were estimated under 2 different assumptions regarding what the average generic lorazepam price would have been in the absence of the alleged conspiracy. To find counterfactual prices, the average per-claim reimbursement for lorazepam for the 4 quarters prior to the alleged conspiracy, $\$ 6.80$, was inflated using (a) the quarterly change in the average per-claim reimbursement for generic alprazolam and (b) the Consumer Price Index (CPI) for all urban consumers, all goods. Potential impact of the alleged conspiracy on the branded lorazepam and generic alprazolam markets was investigated.

RESULTS: The average pre-rebate reimbursements per claim for generic lorazepam were $\$ 10.25, \$ 23.12$, and $\$ 8.48$ in 1991,1998 , and 2009 , respectively. For the same 3 years, $\mathrm{CR}_{4}=52.80,76.02$, and 86.74 , while $\mathrm{HHI}=905.71,2,166.25$, and 2,233.36. Medicaid's excess payments from 1998-2009 were estimated at approximately $\$ 625-\$ 657$ million. The data also suggest the possibility of small impacts on the utilization of branded Iorazepam and the price of generic alprazolam.
CONCLUSIONS: Prior to the alleged conspiracy in 1997, average pre-rebate reimbursement per claim for generic lorazepam was declining, while seller concentration was rising. After a jump in average payment per claim in the years immediately following the alleged conspiracy, prices have gradually returned to their pre-1998 levels. However, the generic lorazepam market was more concentrated in 2009 than prior to the alleged conspiracy.

J Manag Care Pharm. 2012;18(7):506-15

Copyright $\odot 2012$, Academy of Managed Care Pharmacy. All rights reserved.

\section{What is already known about this subject}

- There are often significant cost savings available through the use of generic rather than brand-name drugs. Individual branded lorazepam and alprazolam prescription claims cost Medicaid more than 20 times as much as their generic counterparts in 2009 (pre-rebate). Similar cost savings have been found for many other drugs in different drug classes. On average, in 2010, the price of a generic prescription under Medicaid was approximately oneninth the price of a brand. Cost savings depend on a competitive market structure in which generic drug companies charge low, competitive prices. Concentrated markets, on the other hand, may be susceptible to collusive (implicit or explicit) behavior.

- An alleged conspiracy between Mylan Laboratories and its activeingredient suppliers in 1997 was associated with a rise in concentration in the generic lorazepam market, along with 1998 price escalations by Mylan and other lorazepam producers. The Federal Trade Commission (FTC) alleged that Mylan raised its price of generic lorazepam tablets by amounts ranging approximately from 1,900\%-2,600\%, depending on the bottle size and strength. According to the FTC, Mylan's competitors matched these price increases. In 2002, a \$147 million settlement was reached between Mylan and the FTC.

- Switching from lorazepam to a less expensive benzodiazepine is difficult. First, patients are not very knowledgeable about alternatives. Second, prescribing physicians are often unaware of the prices of available drugs and may be reluctant, especially in the case of a central nervous system drug, to consider a substitution not based on efficacy or safety. 


\section{What this study adds}

- This study describes a counterexample to generic drug cost savings. In the generic lorazepam market, prices dropped slowly after 1998 and did not return to pre-1998 levels for more than a decade. Moreover, as of 2009 , the market structure for generic lorazepam had not returned to the level of concentration observed prior to the alleged Mylan conspiracy; both the 4-firm concentration ratio and the Herfindahl-Hirschman Index exceeded standard accepted cutoffs (40 and 1,000, respectively) for a presumptive competitive market structure in 2009. Because collusion generally is more prevalent in more concentrated markets, the potential for future collusion remains.

- Depending on 2 models with counterfactual scenario assumptions regarding the average generic lorazepam pre-rebate payment per claim in the absence of the alleged conspiracy, the 12-year excess payments for Medicaid were estimated to be between $\$ 624.9$ million and $\$ 657.4$ million in 2009 dollars.

- There was a negligible association between the rise in price in the generic lorazepam market and the per-prescription spending on and utilization of branded lorazepam and generic alprazolam, arguably the 2 closest substitutes for generic lorazepam. A small percentage increase in the use of branded lorazepam and a small transitory increase in the price of generic alprazolam in Medicaid occurred in the years immediately following the alleged conspiracy. Overall, however, there appeared to be limited spillover into these 2 closely related markets.

$\mathrm{T}$ he U.S. system of patent monopoly in the pharmaceutical industry attempts to balance the interests of patients and third-party payers (who want low-cost medicines) with higher prices and profits for pharmaceutical manufacturers. This system grants to pharmaceutical companies patents that bestow monopoly status for a specific period of time commonly known as the "effective patent life," which varies across drugs with an average of about 12 years. ${ }^{1}$ The profits earned during this period of patent protection encourage the development of new drugs by the firms. However, once a drug's patents expire, other generally lower-price generic manufacturers are free to enter the market, and purchasers generally realize significant reductions in prices. ${ }^{2}$ On average in the Medicaid program in 2010 , the price of a generic prescription was approximately one-ninth the price of a brand-name prescription. ${ }^{3}$ Individual branded lorazepam and alprazolam prescription claims cost Medicaid more than 20 times as much as their generic counterparts in 2009 (pre-rebate). ${ }^{4}$

Savings in the use of generic drugs are well known by health policy makers. ${ }^{5}$ Both private and public prescription drug plans encourage the use of generic drugs through a variety of mechanisms. For example, state Medicaid programs include generic drugs on the state's preferred drug list (PDL); mandate generic dispensing of drugs in the absence of a dispense-aswritten (DAW) code; and educate physicians on the use of generic drugs. ${ }^{6}$ Moreover, according to several previous studies, Medicaid has been reasonably successful in switching patients to generic drugs from their branded counterparts fairly quickly following the patent expiration of the branded drug. ${ }^{7-9}$ In fact, Medicaid's generic substitution rate has been estimated in the mid-90th percentile, and generics currently represent approximately $66 \%$ of all Medicaid prescriptions (though only $22 \%$ of Medicaid spending). ${ }^{3}$

However, maximum cost savings for a specific generic drug may not be achieved if the generic market is noncompetitive. This article focuses on generic drug market structure, specifically seller concentration in the Medicaid generic lorazepam market, and its relationship to total spending and spending per prescription claim by Medicaid on this generic drug. On September 30, 1977, branded lorazepam (Ativan), an intermediate-acting benzodiazepine, was approved by the U.S. Food and Drug Administration (FDA) for the treatment of anxiety. ${ }^{10,11}$ Barr Laboratories had the first generic lorazepam tablets approved on December 10, 1985. Mylan Laboratories' generic lorazepam approval came on October 13, 1987. ${ }^{12}$

In a complaint filed 11 years later on February 8, 1999, the Federal Trade Commission (FTC) alleged that Mylan raised its price of generic lorazepam tablets by amounts ranging approximately from 1,900\%-2,600\%, depending on the bottle size and strength. Mylan's competitors were alleged to have matched these price increases. ${ }^{13}$ Four companies-Mylan Laboratories, Cambrex Corporation, Profarmaco S.R.L., and Gyma Laboratories of America-were accused of violating Sections 1 and 2 of the Sherman Antitrust Act by entering into an exclusive licensing agreement that ultimately restrained trade. Specifically, the companies were accused of conspiring to monopolize the markets for the generic drugs lorazepam and clorazepate (a long-acting benzodiazepine). ${ }^{13}$ An alleged agreement made between Mylan and Profarmaco in November 1997 stated that Profarmaco would supply the active pharmaceutical ingredients for lorazepam and clorazepate exclusively to Mylan Laboratories in exchange for a share of the profits obtained by Mylan from the sales of those products. (Cambrex Corporation was the parent company of Profarmaco, and Gyma Laboratories of America distributed Profarmaco products.) The FTC alleged that, through these arrangements and 1998 price escalations, Mylan "[raised] the cost that pharmacies, hospitals, insurers, managed care organizations, wholesalers, government agencies, consumers, and others pay for lorazepam and clorazepate tablets;" the FTC requested "equitable relief" in the amount of $\$ 120$ million plus interest. ${ }^{13}$ In November 2002, a settlement with Mylan Laboratories was approved by the FTC, and a federal district court required Mylan to pay $\$ 147$ million, including \$100 million to "indirect purchasers" (\$71.8 million for consumer claims and $\$ 28.2$ million to state agencies 
including Medicaid), and $\$ 39$ million for attorneys' fees in class action suits filed by private consumers suing under state law. ${ }^{14}$

The present study was conducted to follow up on the generic lorazepam market. We chose not to study the market for generic clorazepate because of its relatively small size (a $\$ 2.0$ million Medicaid market in 1997). ${ }^{4}$ The main purpose of the study was to put the $\$ 147$ million settlement in the context of overall, long-term consumer loss from the high generic lorazepam prices following the alleged conspiracy. The generic lorazepam market never returned to its pre-1997 market structure. Seller concentration has remained high over the last decade. Some of the companies that competed before the alleged conspiracy did not compete afterward. The noncompetitive market structure leaves open the possibility of additional collusion in the future.

\section{Methods}

\section{Data Source}

For the descriptive analysis of the Medicaid generic lorazepam market from 1991-2009, we used the publicly available National Summary Files from the Medicaid State Drug Utilization Data (SDUD) maintained by the Centers for Medicare \& Medicaid Services (CMS). ${ }^{15}$ The database includes pharmacy claims records for outpatient drugs dispensed to Medicaid beneficiaries in 49 states and the District of Columbia. Since the pharmacy claims data are collected as part of the Medicaid Rebate Program, only fee-for-service (FFS) claims are included. States differ in how their drug benefit programs are managed, and the SDUD do not include pharmacy claims from Arizona, which is $100 \%$ managed care. ${ }^{16}$ Other managed care states, however, have pharmacy-benefit carve outs, resulting in FFS claims, in order to take advantage of the federal rebate program. When we summed all Medicaid FFS claims in 2008 in the national database, we found that Medicaid had a total of $\$ 24.3$ billion in (pre-rebate) expenditures on all outpatient prescription drugs.

Each data record in the Medicaid SDUD includes the National Drug Code (NDC), drug name (trade or generic), year and quarter of Medicaid expenditure, number of pharmacy claims, number of units (e.g., individual capsules or tablets), and total pharmacy reimbursement amount (ingredient cost plus dispensing fee plus other fees but no breakout of individual components); the SDUD claims records do not include manufacturer rebates. ${ }^{17}$ The first 5 digits of the NDC number (the labeler code) identify the drug manufacturer, while the remaining digits identify specific drug product by strength, dose formulation, and packaging. We searched the database for all lorazepam products as well as branded lorazepam and generic alprazolam products as the closest substitutes for generic lorazepam. Because the database identifies the companies from which the pharmacies purchased the lorazepam dispensed to Medicaid beneficiaries, quarterly claim counts and pharmacy payment amounts (not accounting for rebates) attributed to each of the generic lorazepam manufacturers were calculated by summing data across individual NDCs for each of the different labeler codes.

\section{Measures of Market Concentration and Price}

A concentration ratio $\left(\mathrm{CR}_{4}\right)$ was calculated as the percentage of generic lorazepam prescriptions accounted for by the top 4 firms (labeler codes). $\mathrm{CR}_{4}$ can range between $\mathrm{O}$ (with an infinite number of small firms) and 100 (where the top 4 firms account for the entire market). In addition, seller concentration was calculated using the Herfindahl-Hirschman Index (HHI), the sum of squared market shares (based on total claims counts) for all firms from which the pharmacies purchased generic lorazepam. The HHI ranges from 0 (an infinite number of small firms) to 10,000 for a pure monopoly (with $100 \%$ of the market). By squaring the market shares, the HHI accounts for market-share inequality (i.e., it gives greater weight to larger market shares). ${ }^{18}$ Because of the HHI's advantages over $\mathrm{CR}_{4}$ for measuring seller concentration, the Department of Justice (DOJ) has adopted the $\mathrm{HHI}$ over the $\mathrm{CR}_{4}$ in its horizontal merger guidelines. ${ }^{19,20}$ Over the time period of this study, when the 1997 Merger Guidelines were in effect, an HHI of less than 1,000 was considered by the DOJ to represent an "unconcentrated" market; 1,000-1,800 indicated that the market was "moderately concentrated;" and more than 1,800 indicated a "highly concentrated" market. ${ }^{19}$

Quarterly per-claim pharmacy reimbursement, as a proxy for drug price, was computed for each manufacturer and overall for lorazepam. The calculation was based on total reimbursed amount (ingredient cost plus dispensing fee plus other fees) pre-rebate.

\section{Calculations}

After converting all values to 2009 dollars using the Consumer Price Index (CPI) for urban consumers, all goods, we summed over the 47 calendar quarters (from 1998 Q2, when Medicaid first experienced the results of the alleged conspiracy-based price increase, through 2009 Q4, the last quarter of data collected) to determine the 12-year total excess payments.

We used 2 different approaches to estimate the counterfactual average payment per lorazepam prescription post-1997 in the absence of the alleged conspiracy. To find counterfactual prices, the average per-claim reimbursement for lorazepam for the 4 quarters prior to the alleged conspiracy, $\$ 6.80$, was inflated using (a) the quarterly change in the average per-claim reimbursement for generic alprazolam (generic alprazolam perclaim reimbursement amounts computed from reimbursement and claims data in the Medicaid SDUD file) and (b) the CPI for urban consumers, all goods. The rationale for the first approach is that it assumes lorazepam prices over time would have been affected by similar "demand and supply forces" as those affecting alprazolam prices. The rationale for the second is that it assumes that real (inflation-adjusted) lorazepam prices over 
Long-Term Medicaid Excess Payments from Alleged Price Manipulation of Generic Lorazepam

TABLE 1 Description of the National Medicaid Generic Lorazepam Market from 1991-2009

\begin{tabular}{|c|c|c|c|c|c|c|c|c|}
\hline Year & $\begin{array}{l}\text { Total Number } \\
\text { of Generic } \\
\text { Lorazepam } \\
\text { Prescriptions in } \\
\text { U.S. (in 1,000s) }{ }^{\mathrm{a}}\end{array}$ & $\begin{array}{l}\text { Total Number of } \\
\text { Medicaid Generic } \\
\text { Lorazepam } \\
\text { Prescriptions } \\
\text { Reimbursed }\end{array}$ & $\begin{array}{l}\text { Total Medicaid } \\
\text { Payments } \\
\text { for Generic } \\
\text { Lorazepam }(\$)^{\mathrm{b}}\end{array}$ & $\begin{array}{c}\text { Average } \\
\text { Payment Per } \\
\text { Prescription } \\
\text { for Generic } \\
\text { Lorazepam }(\$)^{b}\end{array}$ & $\mathrm{CR}_{4}{ }^{\mathrm{c}}$ & $\mathrm{HHI}^{\mathrm{d}}$ & $\begin{array}{l}\text { Number of } \\
\text { Labeler } \\
\text { Codes }\end{array}$ & $\begin{array}{c}\text { Number of } \\
\text { Labeler Codes } \\
\text { with } \geq 1 \% \\
\text { of Medicaid } \\
\text { Market }\end{array}$ \\
\hline 1991 & na & $1,415,890$ & $14,516,510$ & 10.25 & 52.80 & 905.71 & 41 & 16 \\
\hline 1992 & na & $1,896,115$ & $19,395,701$ & 10.23 & 54.92 & 961.24 & 43 & 14 \\
\hline 1993 & na & $2,177,388$ & $17,811,391$ & 8.18 & 57.46 & $1,025.23$ & 38 & 16 \\
\hline 1994 & na & $2,231,157$ & $17,652,665$ & 7.91 & 59.22 & $1,096.45$ & 36 & 15 \\
\hline 1995 & na & $2,268,928$ & $17,709,799$ & 7.81 & 59.83 & $1,130.84$ & 35 & 15 \\
\hline 1996 & na & $2,488,634$ & $17,289,274$ & 6.95 & 58.79 & $1,175.50$ & 39 & 13 \\
\hline 1997 & na & $2,644,807$ & $18,515,317$ & 7.00 & 66.36 & $1,465.24$ & 40 & 14 \\
\hline 1998 & na & $2,804,349$ & $64,827,824$ & 23.12 & 76.02 & $2,166.25$ & 39 & 13 \\
\hline 1999 & na & $3,019,274$ & $91,315,955$ & 30.24 & 83.40 & $2,447.78$ & 30 & 8 \\
\hline 2000 & 16,842 & $3,215,127$ & $96,639,375$ & 30.06 & 83.93 & $2,126.31$ & 31 & 7 \\
\hline 2001 & 17,702 & $3,778,047$ & $100,934,654$ & 26.72 & 85.75 & $2,046.97$ & 32 & 7 \\
\hline 2002 & 17,453 & $4,035,466$ & $96,818,447$ & 23.99 & 78.56 & $1,797.50$ & 31 & 8 \\
\hline 2003 & 17,545 & $4,257,529$ & $93,099,961$ & 21.87 & 81.42 & $1,861.24$ & 27 & 7 \\
\hline 2004 & 18,436 & $4,401,819$ & $85,093,949$ & 19.33 & 81.41 & $1,946.98$ & 26 & 6 \\
\hline 2005 & 19,002 & $4,326,616$ & $79,027,327$ & 18.27 & 85.73 & $2,050.98$ & 25 & 6 \\
\hline 2006 & 19,789 & $5,504,358$ & $66,523,326$ & 12.09 & 94.40 & $2,393.22$ & 28 & 5 \\
\hline 2007 & 21,022 & $4,276,290$ & $55,600,057$ & 13.00 & 93.27 & $2,359.12$ & 27 & 5 \\
\hline 2008 & 22,043 & $4,400,862$ & $46,692,296$ & 10.61 & 91.07 & $2,416.30$ & 29 & 5 \\
\hline 2009 & 22,436 & $4,327,388$ & $36,703,876$ & 8.48 & 86.74 & $2,233.36$ & 22 & 7 \\
\hline \multicolumn{9}{|c|}{$\begin{array}{l}\text { aThe total number of generic lorazepam prescriptions in the United States was found for various years at http://drugtopics.modernmedicine.com/ } \\
\text { Pharmacy+Facts+E+Figures. }{ }^{21} \text { The reports for various years were entitled Top } 200 \text { Generic Drugs by Total Prescriptions. } \\
\text { b. Average payment estimate includes ingredient cost plus fees and does not account for manufacturer rebates. } \\
{ }^{c} C R_{4}(4-f i r m \text { concentration ratio) is computed as the share of Medicaid-reimbursed prescriptions accounted for by the top } 4 \text { manufacturer labels. } \\
{ }^{H} H H I \text { (Herfindahl-Hirschman Index) is computed as the sum of squared market shares of Medicaid-reimbursed prescriptions of all the manufacturer labels } \\
\text { (e.g., } 41 \text { labels in } 1991 \text { and } 22 \text { labels in 2009). } \\
\text { na=not available. }\end{array}$} \\
\hline
\end{tabular}

time would have remained constant. Such a counterfactual price would not be affected by alleged conspiracy-based spillover into the generic alprazolam market.

All the data analyses were conducted using the SAS software package for Windows (Version 9.2, SAS Institute Inc., Cary, NC) and Excel 2007 (Microsoft, Redmond, WA).

\section{Results}

\section{The Evolving Medicaid Generic Lorazepam Market}

In 1991, the \$14.5 million Medicaid generic lorazepam market (excluding branded lorazepam, which had a very small share of the Medicaid lorazepam market by that time- $0.60 \%$ of claims and $10.82 \%$ of spending) had more than 35 suppliers with 41 different labeler codes (a few firms had several different labeler codes), with 16 labeler codes (15 firms) each having at least a $1 \%$ market share (Table 1). ${ }^{21}$ With an HHI of 905.71, the market would be considered presumptively competitive according to both the 1997 Merger Guidelines (in effect during our study period) ${ }^{19}$ and the more recent 2010 Merger Guidelines. ${ }^{20}$ The average price of $\$ 10.25$ per generic lorazepam prescription in 1991 was $73 \%$ less than the average price of $\$ 38.55$ per branded lorazepam prescription (data presented later).

In 1997, the Medicaid generic lorazepam market had grown to 2.6 million prescriptions and $\$ 18.5$ million in total prerebate Medicaid spending (Table 1). The average price per prescription had fallen to $\$ 7.00$. The number of firms participating in the Medicaid market had not fallen much; there were 14 labeler codes with at least 1\% of the market. However, relative to 1991, market concentration had increased, with $\mathrm{HHI}=1,465.24$, considered moderately concentrated under the 1997 Merger Guidelines ${ }^{19}$ (competitive under the 2010 Merger Guidelines $^{20}$ ). In 1998, Medicaid experienced a 250\% increase in spending on lorazepam from $\$ 18.5$ million to $\$ 64.8$ million. Whereas the number of prescriptions rose by $6.03 \%$ from 1997 to 1998 , the average prescription price increased to $\$ 23.12$ in 1998 from $\$ 7.00$ in 1997, representing a 230\% increase, as state Medicaid programs began to adjust their maximum allowable cost (MAC) for generic lorazepam. ${ }^{22}$ That year, the HHI rose above 2,000, considered concentrated by the 1997 Merger Guidelines ${ }^{19}$ (and moderately concentrated under the 2010 Merger Guidelines ${ }^{20}$ ). In 1999 and 2000, Medicaid was spending more than $\$ 30$ per prescription for generic loraz- 
TABLE 2 Prescription Share for the Top 7 Labeler Codes for National Medicaid Generic Lorazepam: 1997-2002

\begin{tabular}{|c|c|c|c|c|c|c|}
\hline \multirow[b]{2}{*}{ Labeler Rank } & \multicolumn{6}{|c|}{ Year } \\
\hline & 1997 & 1998 & 1999 & 2000 & 2001 & 2002 \\
\hline \multicolumn{7}{|c|}{1} \\
\hline NDC labeler code & 00378 & 00378 & 00378 & 00378 & 00781 & 00781 \\
\hline Manufacturer & $\begin{array}{c}\text { Mylan } \\
\text { Labs }\end{array}$ & $\begin{array}{c}\text { Mylan } \\
\text { Labs }\end{array}$ & $\begin{array}{c}\text { Mylan } \\
\text { Labs }\end{array}$ & $\begin{array}{c}\text { Mylan } \\
\text { Labs }\end{array}$ & Sandoz & Sandoz \\
\hline Rx share (\%) & 24.96 & 39.74 & 41.26 & 32.56 & 27.50 & 26.50 \\
\hline \multicolumn{7}{|c|}{2} \\
\hline NDC labeler code & 00228 & 00228 & 00781 & 00781 & 00378 & 00378 \\
\hline Manufacturer & $\begin{array}{c}\text { Actavis } \\
\text { Elizabeth } \\
\end{array}$ & $\begin{array}{c}\text { Actavis } \\
\text { Elizabeth } \\
\end{array}$ & Sandoz & Sandoz & $\begin{array}{c}\text { Mylan } \\
\text { Labs }\end{array}$ & $\begin{array}{c}\text { Mylan } \\
\text { Labs }\end{array}$ \\
\hline Rx share (\%) & 23.35 & 19.40 & 21.49 & 25.09 & 27.13 & 24.76 \\
\hline \multicolumn{7}{|c|}{3} \\
\hline NDC labeler code & 51875 & 52544 & 00228 & 52544 & 52544 & 52544 \\
\hline Manufacturer & $\begin{array}{l}\text { Royce } \\
\text { Labs }\end{array}$ & Watson & $\begin{array}{c}\text { Actavis } \\
\text { Elizabeth }\end{array}$ & Watson & Watson & Watson \\
\hline Rx share (\%) & 9.26 & 8.61 & 12.60 & 14.01 & 17.94 & 13.91 \\
\hline \multicolumn{7}{|c|}{4} \\
\hline NDC labeler code & 00182 & 00781 & 59911 & 00228 & 00228 & 00228 \\
\hline Manufacturer & $\begin{array}{c}\text { Goldline } \\
\text { Labs }\end{array}$ & Sandoz & Wyeth & $\begin{array}{c}\text { Actavis } \\
\text { Elizabeth }\end{array}$ & $\begin{array}{c}\text { Actavis } \\
\text { Elizabeth }\end{array}$ & $\begin{array}{c}\text { Actavis } \\
\text { Elizabeth }\end{array}$ \\
\hline Rx share (\%) & 8.79 & 8.26 & 8.04 & 12.27 & 13.17 & 13.38 \\
\hline \multicolumn{7}{|c|}{5} \\
\hline NDC labeler code & 00536 & 00182 & 52544 & 59911 & 59911 & 00591 \\
\hline Manufacturer & $\begin{array}{l}\text { Rugby } \\
\text { Labs }\end{array}$ & $\begin{array}{c}\text { Goldline } \\
\text { Labs }\end{array}$ & Watson & Wyeth & Wyeth & Watson \\
\hline Rx share (\%) & 6.01 & 4.34 & 6.75 & 8.97 & 6.55 & 8.25 \\
\hline \multicolumn{7}{|c|}{6} \\
\hline NDC labeler code & 00781 & 51875 & 51079 & 51079 & 53489 & 63304 \\
\hline Manufacturer & Sandoz & $\begin{array}{c}\text { Royce } \\
\text { Labs }\end{array}$ & UDL & UDL & Mutual & Ranbaxy \\
\hline Rx share (\%) & 5.71 & 3.98 & 2.71 & 2.39 & 3.23 & 5.19 \\
\hline \multicolumn{7}{|c|}{7} \\
\hline NDC labeler code & 52544 & 00536 & 51875 & 53489 & 51079 & 53489 \\
\hline Manufacturer & Watson & $\begin{array}{l}\text { Rugby } \\
\text { Labs }\end{array}$ & $\begin{array}{l}\text { Royce } \\
\text { Labs }\end{array}$ & Mutual & UDL & Mutual \\
\hline Rx share (\%) & 5.70 & 3.87 & 1.55 & 1.29 & 2.11 & 3.21 \\
\hline $\begin{array}{l}\text { Total for top } 4 \\
\text { suppliers (\%) } \\
\end{array}$ & 66.36 & 76.02 & 83.40 & 83.93 & 85.75 & 78.56 \\
\hline $\begin{array}{l}\text { Total for top } 7 \\
\text { suppliers (\%) }\end{array}$ & 83.78 & 88.21 & 94.41 & 96.58 & 97.64 & 95.21 \\
\hline
\end{tabular}

NDC = National Drug Code $; \mathrm{Rx}=$ prescription .

epam, and $\mathrm{CR}_{4}$ rose above 80 (well above a competitive cutoff of 40 or "loose oligopoly" cutoff of $\left.60^{18}\right)$. The HHI reached $2,447.78$ in 1999, its highest value over the 2 decades. By the year 2000, there were only 7 labeler codes that held at least $1 \%$ of the Medicaid generic lorazepam market. From 1999 to 2003, Medicaid spent more than $\$ 90$ million annually on generic lorazepam. In 2001, Medicaid spent more than $\$ 100$ million.

Over the last decade, following the FTC settlement, the Medicaid average reimbursement per generic lorazepam claim has come down slowly, to $\$ 8.48$ in 2009 , near the pre-1998 levels. In 2009, Medicaid spent $\$ 36.7$ million for 4.3 million prescriptions. However, the market structure has not returned to the pre-1998 structure because in 2009 the top 4 firms accounted for $86.74 \%$ of the prescriptions and $\mathrm{HHI}=2,233.36$. Note that there was no drop in the number of generic lorazepam prescriptions for which Medicaid reimbursed in 2006 as might have been expected with the movement of individuals dually eligible for Medicaid and Medicare Part D to Medicare Part D in January 2006. Because Medicare Part D does not provide coverage for benzodiazepines, Medicaid was left with the primary public burden for these drugs even after $2006 .{ }^{23}$ It is unlikely, however, that by 2006 there was much utilization of benzodiazepines by elderly Medicaid beneficiaries. Benzodiazepines have a significant effect on cognitive impairment, balance, and somnolence, resulting in their placement on the Beers List, which is a list of medications that are generally considered to be inappropriate for use by elderly patients..$^{24,25}$

Table 2 shows the top firms in the lorazepam market during the years surrounding the alleged conspiracy. Mylan had the highest Medicaid market share from 1997 to 2000, commanding more than $40 \%$ of the market in 1999. In 2001, Mylan dropped to second place, following Sandoz, but it still held a $24.76 \%$ market share in 2002. Whereas Actavis Elizabeth dropped in rank over the 6 years, Watson rose in the rankings, with 2 labeler codes among the top 7 in 2002. Royce Labs, Rugby Labs (both now subsidiaries of Watson Pharmaceuticals), and Goldline Labs (now a subsidiary of Teva Pharmaceuticals) essentially dropped out of the market after the 1990s.

\section{Long-Term Medicaid Excess Payments Associated with the Alleged Conspiracy}

Table 3 gives the estimated excess payments by Medicaid under 2 different counterfactual scenario assumptions regarding what the average Medicaid (pre-rebate) payment for a generic lorazepam claim would have been without the alleged conspiracy: (1) the average payment per claim in the 4 quarters prior to 1998 Q2 (\$6.80) adjusted for the percentage change in average payment per claim for generic alprazolam (lorazepam's closest generic substitute) over the same time period and (2) the average payment per claim in the 4 quarters prior to 1998 Q2 (\$6.80) adjusted for the rate of inflation (using the CPI for urban consumers, all goods). In 2009 dollars, estimated total excess Medicaid FFS payments over the full 12-year period are $\$ 624.9$ million under the generic alprazolam counterfactual payment assumption. Under counterfactual scenario 2, the estimated total of excess Medicaid FFS payments over the full 12 -year period is $\$ 657.4$ million. If we were to assume an $11 \%$ manufacturer rebate on Medicaid spending for generic lorazepam over the 19-year period, the estimated excess payments are $\$ 556.1$ million and $\$ 585.0$ million under counterfactual 
Long-Term Medicaid Excess Payments from Alleged Price Manipulation of Generic Lorazepam

TABLE 3 Excess Medicaid Payments for Generic Lorazepam, 1998-2009

Counterfactual Price Scenarios

\begin{tabular}{|c|c|c|c|c|}
\hline \multirow[b]{3}{*}{ Year } & \multirow{2}{*}{\multicolumn{2}{|c|}{$\begin{array}{c}\text { Pre-1998 Generic Lorazepam Price + Adjustment } \\
\text { Based on Alprazolam Price Change }\end{array}$}} & \multirow{2}{*}{\multicolumn{2}{|c|}{$\begin{array}{l}\text { Pre-1998 Generic Lorazepam Price + Adjustment } \\
\text { Based on CPI for Urban Consumers, All Goods }\end{array}$}} \\
\hline & & & & \\
\hline & $\begin{array}{c}\text { Average Quarterly } \\
\text { Counterfactual Price }(\$)^{\mathrm{a}}\end{array}$ & $\begin{array}{l}\text { Post-1997 Annual Excess } \\
\text { Payments }(2009 \$)^{\mathrm{b}}\end{array}$ & $\begin{array}{c}\text { Average Quarterly } \\
\text { Counterfactual Price }(\$)^{c}\end{array}$ & $\begin{array}{l}\text { Post-1997 Annual Excess } \\
\text { Payments }(2009 \$)^{\mathrm{b}}\end{array}$ \\
\hline 1998 & 7.26 & $58,595,220$ & 6.84 & $59,772,776$ \\
\hline 1999 & 8.16 & $85,569,975$ & 6.97 & $90,212,046$ \\
\hline 2000 & 7.71 & $89,502,500$ & 7.21 & $91,493,516$ \\
\hline 2001 & 9.77 & $77,144,827$ & 7.41 & $88,068,972$ \\
\hline 2002 & 7.44 & $79,482,328$ & 7.53 & $79,051,471$ \\
\hline 2003 & 8.76 & $64,925,731$ & 7.70 & $70,262,051$ \\
\hline 2004 & 8.28 & $55,089,732$ & 7.91 & $56,935,497$ \\
\hline 2005 & 8.32 & $47,003,530$ & 8.17 & $47,718,330$ \\
\hline 2006 & 8.84 & $32,174,986$ & 8.44 & $33,973,827$ \\
\hline 2007 & 10.38 & $22,012,671$ & 8.68 & $27,873,844$ \\
\hline 2008 & 8.71 & $15,764,089$ & 9.01 & $14,713,244$ \\
\hline 2009 & 8.89 & $-2,415,180$ & 8.98 & $-2,717,548$ \\
\hline 12-year total Medicaidd & & $624,850,411$ & & $657,358,027$ \\
\hline
\end{tabular}

aFor 1998 22, the counterfactual price was set at \$6.80, the average per-claim payment for generic lorazepam across the previous 4 calendar quarters: 1997 Q2 (\$6.72), 1997 Q3 (\$6.79), 1997 Q4 (\$6.65), and 1998 Q1 (\$7.04). The counterfactual price for 1998 Q3 was computed as \$6.80 times 1 plus the proportional change in the perclaim payment for generic alprazolam between 1998 Q2 and 1998 Q3. Each subsequent quarter's price was found similarly. The values shown in Table 3 are the averages of the quarterly counterfactual prices for the years 1998-2009 (average over 3 quarters in 1998 and over 4 quarters each year from 1999-2009).

${ }^{b}$ The estimate of annual post-1997 excess payments is the sum of 4 calendar quarters' post-1997 excess payments (except for 1998 when the sum is over 3 calendar quarters' excess payments). Quarterly post-1997 excess payments are estimated by multiplying the number of Medicaid-reimbursed generic lorazepam prescriptions during the quarter times the difference between the quarterly average payment for generic lorazepam and the quarterly assumed counterfactual price. Excess payment estimates were then inflated to 2009 dollars using the CPI for urban consumers, all goods. Note that values in Table 3 cannot be determined simply by multiplying number of prescription claims (Table 1) by the difference between actual lorazepam prices (Table 1) and the counterfactual prices (Table 3) because of the annual averages, rather than quarterly values, presented in the tables.

${ }^{c}$ For 1998 Q2, the counterfactual price was set at \$6.80, the average per-claim payment for generic lorazepam across the previous 4 calendar quarters: 1997 Q2 through 1998 Q1. The counterfactual price for 1998 Q3 was computed as $\$ 6.80$ times 1 plus the inflation rate from 1998 Q2 to 1998 Q3, found using the CPI for urban consumers, all goods. Each subsequent quarter's price was found similarly. The values shown in Table 3 are the averages of the quarterly counterfactual prices for the years 19982009 (average over 3 quarters in 1998 and over 4 quarters each year from 1999-2009).

dThe 12-year total excess payments for Medicaid are found by summing the annual excess payments.

CPI = Consumer Price Index.

scenarios 1 and 2, respectively. These values are each 89\% of the pre-rebate estimates.

For completeness, we also looked at the utilization and price trends for branded lorazepam and generic alprazolam, the 2 closest substitutes for generic lorazepam. Figures 1 and 2 show utilization and price trends, respectively. Whereas we might have expected the utilization of generic alprazolam to skyrocket following the steep rise in the price of generic lorazepam, that seems not to be the case (Figure 1). The steadily rising utilization trend for alprazolam remains undisturbed by changes in the generic lorazepam market. Interestingly, although the absolute number of claims for branded lorazepam remained tiny over the entire study period, we do observe a steep percentage rise in the utilization of branded lorazepam beginning in 1998 Q1. The number of prescriptions rose from 1,062 in 1997 Q4 to 26,122 in $1998 \mathrm{Q} 1$ and to more than 40,000 in the first two quarters of 1999 , representing approximately $5 \%$ of all lorazepam (brand plus generic) prescriptions for that 6-month period. Utilization remained in excess of 20,000 prescriptions per quarter until 2001 Q2. During 1999 Q1 and 1991 Q2, the average reimbursed amounts per prescription for branded lorazepam were $\$ 56.24$ and $\$ 57.69$, respectively, less than twice the $\$ 30$ average price of lorazepam (without considering the potentially larger rebates for branded lorazepam), as state Medicaid programs adjusted their MACs.

The association of the alleged conspiracy with prices may be seen in Figure 2. Note that there were so few prescriptions of branded lorazepam (<100 for some quarters) from 2007 Q1 through 2008 Q4, average price per prescription could not be reliably calculated, hence, there is a gap in the trend line between 2006 and 2009. Regardless, the branded lorazepam price trend seems unaffected by events in the generic lorazepam market in the late 1990s. The price of generic alprazolam declined from \$38.16 in 1993 Q3 (the first quarter of generic entry in Medicaid following the patent expiration for branded alprazolam) to \$6.98 in 1998 Q2. Payment per prescription then rose, following the alleged conspiracy in the generic lorazepam market, to \$8.26 in 1998 Q4, then \$9.18 in 1999 Q1, and 
Long-Term Medicaid Excess Payments from Alleged Price Manipulation of Generic Lorazepam

\section{FIGURE 1 Utilization of Closest Lorazepam Substitutes in Medicaid: 1991-2009}

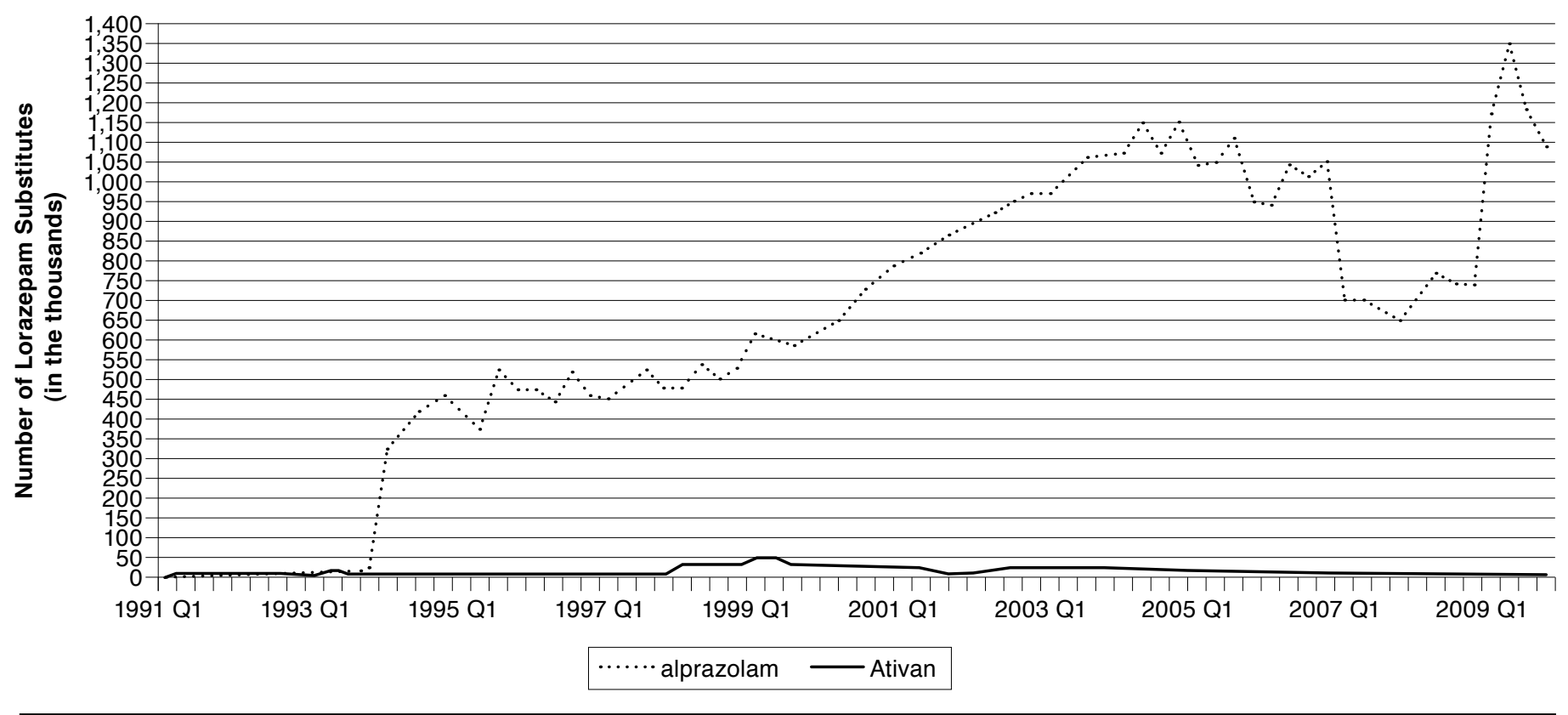

$\$ 8.53$ in 1999 Q2. Hence, the data suggest the possibility of a small impact on the price of generic alprazolam.

\section{Discussion}

A long, rich literature has shown that, in general, across many different drug classes, as the number of generic entrants rises, the market price approaches the competitive price (or marginal cost). ${ }^{26-29}$ With scores of generic manufacturers, from all over the world and of varying sizes, supplying many of the larger drug markets (e.g., fluoxetine, simvastatin, and risperidone), the expectation that pricing is competitive is a reasonable one.

With a small number of firms, however, competitive pricing should not be taken for granted. In the face of large potential monopoly profits, it is much more likely that implicit or explicit collusion will occur. With high enough seller concentration, firms are few enough to recognize their interdependence and, through such interdependence, "agree" on the profit-maximizing monopoly price. ${ }^{18}$

When it comes to the number of firms, how small is "small"? Searching for a critical concentration ratio has intrigued many scholars in industrial-organization economics over the years, although there seems to be no "one size fits all" that antitrust authorities can rely on for every market. ${ }^{30-33}$ Moreover, the notion of a critical concentration ratio may be more realistic than assuming a smooth transition between monopoly and competitive pricing. In 1997, the year before the generic lorazepam price rise, $\mathrm{CR}_{4}$ was 66.36 . It jumped another 10 percentage points in 1998. At approximately $\mathrm{CR}_{4}=70$ (the "critical concentration ratio"), the generic lorazepam oligopolists, through an alleged explicit collusive scheme plus alleged price-leadership behavior (other firms following Mylan's price increase), were able to increase price. Although consumers are no longer paying such high prices for generic lorazepam, the extremely high seller concentration that still existed in 2009 makes it more likely that another steep price rise could occur in the future than if the seller concentration had returned to its pre-1998 level.

Because of the nature of drug markets, if generic drug prices are high for any reason, most consumers cannot expect much relief in substitute markets. In the case of this class of psychotropic drugs without any direct-to-consumer advertising, patients are not very knowledgeable about alternatives. Meanwhile, the prescribing physicians are often unaware of the prices of available drugs. ${ }^{34}$ Finally, without a body of solid comparative effectiveness research that can equate the efficacy and safety profiles of chemically distinct agents, payers (including Medicare, Medicaid, and private insurance companies) are reluctant to override a doctor's choice of medication. Although prior authorization schemes can be implemented, they are expensive to administer ${ }^{35}$ and can inhibit access to medication. ${ }^{6}$ In the case of the generic lorazepam market, comparative effectiveness studies of alprazolam versus lorazepam would have gone a long way to mitigate the burden of the alleged Mylan conspiracy. Payers would have felt comfortable enforcing a switch to the more reasonably priced generic alprazolam following the price jump in the generic lorazepam market. 
Long-Term Medicaid Excess Payments from Alleged Price Manipulation of Generic Lorazepam

\section{FIGURE 2 Price-Per-Prescription of Closest Lorazepam Substitutes in Medicaid: 1991-2009}

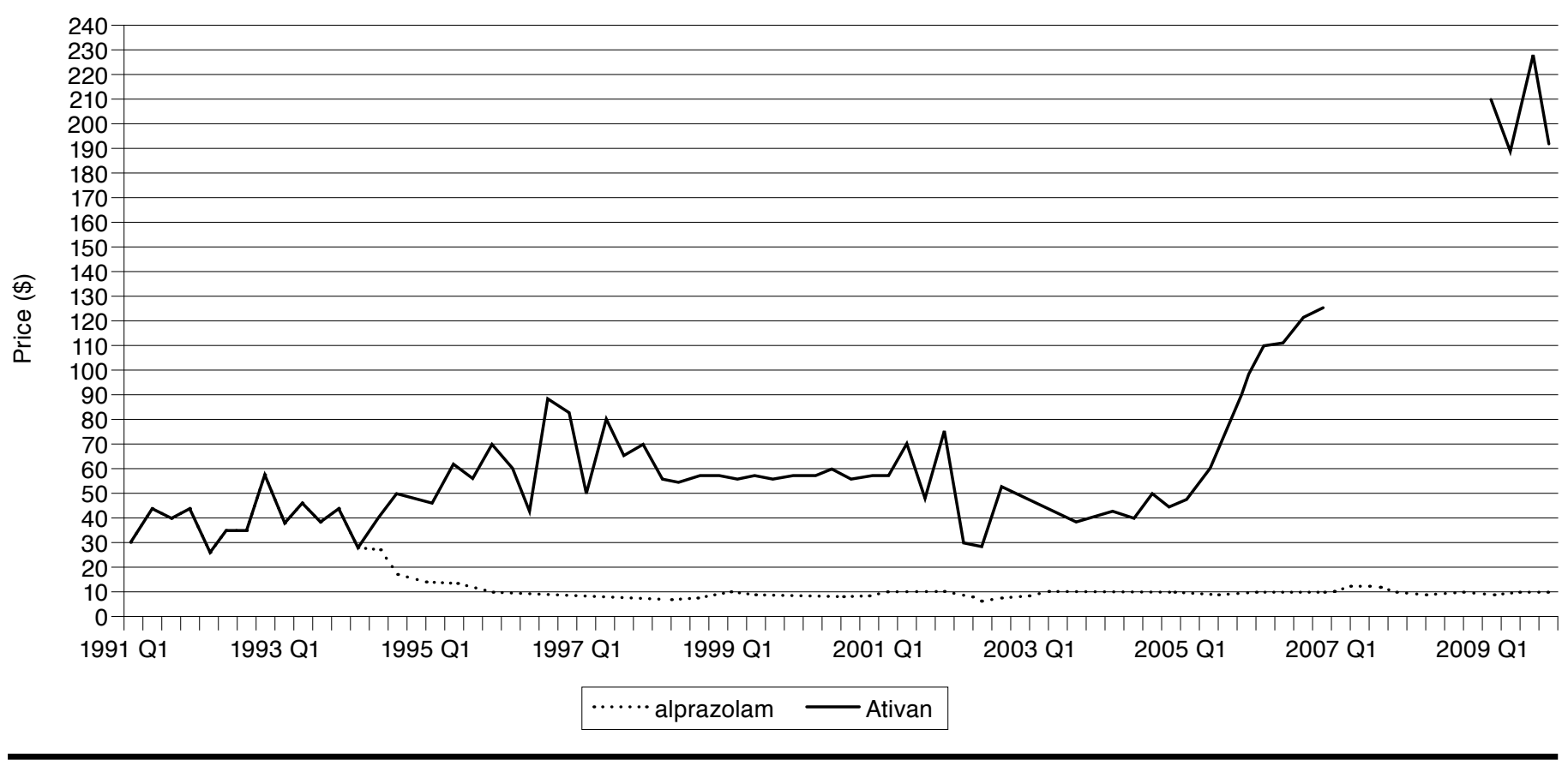

Empirical evidence strongly suggests substitution difficulty. Drug prices are not generally affected by either (a) the entry of new drugs in a therapeutic class or (b) the entry of a new class of drugs approved for the same indication. ${ }^{8,9}$

It is tempting to try to estimate the overall excess cost to U.S. payers. After all, pharmacies after the alleged price conspiracy were paying the same inflated prices for generic lorazepam regardless of ultimate payer. Although some uninsured individuals may have stopped purchasing the drug, it seems clear from Table 1, for the years in which we have utilization data for the United States, that national utilization of generic lorazepam rose over time, implying that at least most payers were covering the cost. Naiively noticing that the ratio of total prescriptions for generic lorazepam to Medicaid-covered prescriptions ranged from 3.6-5.2 over the years, we would guess at an approximate $\$ 2.5$ billion ( $\$ 625$ million $\times 4$ ) total excess cost to U.S. payers.

\section{Limitations}

This study is limited primarily by the nature of Medicaid claims data. First, spending data are pre-rebate, and we do not have access to rebate information. The Medicaid Drug Rebate Program, established by the Omnibus Budget Reconciliation Act of 1990, requires a drug manufacturer to enter into and have in effect a national rebate agreement with the Secretary of the Department of Health and Human Services in order for states to receive federal funding for outpatient drugs dispensed to Medicaid patients. ${ }^{36}$ Rebate percentages are based on average manufacturer prices (AMPs), the average price wholesalers pay manufacturers for drugs sold to retail pharmacies; the percentage is higher for innovator drugs than for noninnovator drugs. (For generic lorazepam, rebates can be assumed to have been $11 \%$ of AMP over the study period. ${ }^{36}$ ) In addition, a number of states have been collecting state-only supplemental rebates in conjunction with a PDL. ${ }^{37}$ To the extent that we have been unable to account for generic lorazepam rebates, we have overstated the extent of excess Medicaid FFS payments. The extent of the overestimate is easily computed, however, as shown in the Results section, depending on one's assumption about Medicaid-captured rebates.

A second, fundamental limitation of this study is that it is not possible to know what Medicaid payment rates actually would have prevailed over the period 1998-2009 in the absence of the alleged conspiracy. Our estimates of excess Medicaid FFS payments rely on counterfactual scenarios projecting what Medicaid payments "would have been" under 2 different assumptions. The plausibility of our estimates of total excess Medicaid payments is entirely dependent on the plausibility of our counterfactual scenarios.

A third limitation of the study is that paid claims include not only drug ingredient cost but also fees associated with the claim. Moreover, although we have treated reimbursement per 
claim as a reasonable proxy for price, prescriptions may vary in size, for example, a 2 -week versus 30 -day supply. To the extent that fees represent different percentages of the prescription cost over time or to the extent that the size distribution of prescriptions varies over time, our estimates may be biased.

Fourth, although we think that we have captured most of the outpatient prescriptions reimbursed for Medicaid beneficiaries, we realize that the database is not complete. The proportion of total Medicaid beneficiaries in managed care plans has risen significantly, from only $9.5 \%$ in 1991 to $40.1 \%$ in $1996^{38}$ and $71.7 \%$ in $2009 .{ }^{39}$ We did not determine the extent to which the national Medicaid FFS database that we used includes managed Medicaid pharmacy benefits that are carved out of managed care. Because the database includes only claims from Medicaid FFS, some of the trends observed in our results could be an artifact of a shrinking share of total Medicaid recipients in FFS plans.

\section{Conclusions}

Excess payments for generic lorazepam stemming from the alleged Mylan-supplier conspiracy in 1997 lasted for more than a decade. The $\$ 147$ million (approximately $\$ 232$ million in 2009 dollars) penalty was substantially less than our estimates of excess Medicaid payments over the period 1998-2009. Both competition policy makers and health policy makers need to be aware that generic markets are not necessarily competitive markets offering consumers and payers marginal-cost prices.

\section{Authors}

BOYANG BIAN, BPharm, MS, is a Doctoral Candidate; JEFF J. GUO, PhD, is Professor of Pharmacoeconomics \& Pharmacoepidemiology; and JILL MARTIN BOONE, PharmD, is Professor of Pharmacy Practice, James L. Winkle College of Pharmacy, University of Cincinnati Academic Health Center, Cincinnati, Ohio. ELIZABETH GOREVSKI, PharmD, MS, is Clinical Research Pharmacist, Cincinnati Veterans Administration Medical Center, Cincinnati, Ohio; CHRISTINA M.L. KELTON, $\mathrm{PhD}$, is Professor of Economics, Carl H. Lindner College of Business, and Adjunct Professor of Clinical Pharmacy, James L. Winkle College of Pharmacy, University of Cincinnati, Cincinnati, Ohio.

AUTHOR CORRESPONDENCE: Christina M.L. Kelton, PhD, Professor of Economics and Adjunct Professor of Clinical Pharmacy, University of Cincinnati, Carl H. Lindner College of Business, 414 Lindner Hall, 2925 Campus Green Dr., P.O. Box 210195, Cincinnati, Ohio, 45221-0195. Tel: 513.556.2983; E-mail: chris.kelton@uc.edu.

\section{DISCLOSURES}

This research had no external funding, and the authors report no conflicts of interest. Study concept and design were contributed equally by Bian, Gorevski, Kelton, and Boone. Bian had primary responsibility for data collection, with assistance from Guo. Data interpretation was primarily the work of Bian and Kelton, with assistance from Gorevski. The manuscript was written primarily by Kelton, with assistance from Gorevski and Bian and was revised by all authors but Boone.

\section{ACKNOWLEDGMENTS}

An earlier version of this study was presented as an unpublished poster at the Annual Meeting of the International Society for Pharmacoeconomics and Outcomes Research in Washington, D.C., June 2012. We would like to thank 4 anonymous referees for this journal, who significantly contributed both to the substance and the readability of the final draft of this article.

\section{REFERENCES}

1. Grabowski HG, Vernon JM. Effective patent life in pharmaceuticals. Intl J Tech Mgmt. 2000;19(1/2):98-120

2. Cook A. How increased competition from generic drugs has affected prices and returns in the pharmaceutical industry. Congressional Budget Office Report. July 1998. Available at: http://www.cbo.gov/sites/default/files/ cbofiles/ftpdocs/6xx/doc655/pharm.pdf. Accessed August 25, 2012.

3. Coster JM. Trends in generic drug reimbursement in Medicaid and Medicare. US Pharm. 2010;35(6; Generic Drug Review suppl):14-19. Available at: http://www.uspharmacist.com/content/s/127/c/21147/. Accessed August 25, 2012.

4. Gorevski E, Bian B, Kelton CM, Martin Boone JE, Guo JJ. Utilization, spending, and price trends for benzodiazepines in the US Medicaid program: 1991-2009. Ann Pharmacother. 2012;46(4):503-12.

5. U.S. Government Accountability Office. Drug pricing: research on savings from generic drug use. Letter to The Honorable Orrin G. Hatch. January 31, 2012. Available at: http://www.gao.gov/assets/590/588064.pdf. Accessed August 25, 2012.

6. Crowley JS, Ashner D, Elam L. Medicaid outpatient prescription drug benefits: findings from a national survey, 2003. Kaiser Commission on Medicaid and the Uninsured. December 2003. Available at: http://www. kff.org/medicaid/upload/Medicaid-Outpatient-Prescription-Drug-BenefitsFindings-from-a-National-Survey-2003.pdf. Accessed August 25, 2012.

7. Ferrand Y, Kelton CML, Guo JJ, Levy MS, Yu Y. Using time-series intervention analysis to understand U.S. Medicaid expenditures on antidepressant agents. Res Social Adm Pharm. 2011;7(1):64-80.

8. Guo JJ, Kelton CML. Competition between brand-name and generic drugs. In: Fulda TR, Wertheimer A, eds. Handbook of Pharmaceutical Public Policy. New York, NY: Haworth Press; 2007:395-416.

9. Guo JJ, Kelton CML, Pasquale MK, et al. Price and market-share competition of anti-ulcer gastric medications in the Ohio Medicaid market. Intl J Pharm Med. 2004;18(5):271-82.

10. U.S. Food and Drug Administration. Drugs@FDA. Ativan. Available at: http://www.accessdata.fda.gov/scripts/cder/drugsatfda/index. cfm?fuseaction=Search.DrugDetails. Accessed August 25, 2012.

11. Drugs.com. Lorazepam tablets, USP CIV. Available at: http://www.drugs. com/pro/lorazepam.html. Accessed August 25, 2012

12. U.S. Pharmacopeial Convention. United States Pharmacopeia Dispensing Information: USP DI, Vol. 3. Rockville, MD: USP; 1995.

13. Federal Trade Commission. FTC v. Mylan Laboratories, Inc., Cambrex Corporation, Profarmaco S.R.I., and Gyma Laboratories of America, Inc.: Amended complaint. February 8, 1999. Available at: http://www.ftc.gov/ os/1999/02/mylanamencmp.htm. Accessed August 25, 2012 
14. Park DK, Wolfram R. The FTC's use of disgorgement in antitrust actions threatens to undermine the efficient enforcement of the federal antitrust law. The Antitrust Source. 2002;September:1-14. Available at: http://www.americanbar.org/content/dam/aba/publishing/antitrust_source/disgorgement.authcheckdam.pdf. Accessed August 25, 2012.

15. Centers for Medicare \& Medicaid Services. Medicaid drug rebate program data: state utilization data. Updated August 14, 2012. Available at: http://www.medicaid.gov/Medicaid-CHIP-Program-Information/By-Topics/ Benefits/Prescription-Drugs/Medicaid-Drug-Rebate-Program-Data.html. Accessed August 25, 2012.

16. The Lewin Group. Medicaid managed care cost savings-a synthesis of fourteen studies. Prepared for America's Health Insurance Plans. July 2004. Available at: http://www.ahip.org/Medicaid-Cost-Savings/. Accessed August 25, 2012.

17. Centers for Medicare $\&$ Medicaid Services. Medicaid state drug utilization data: web file structure and definitions, August 2009. Available at: http://www.medicaid.gov/Medicaid-CHIP-Program-Information/By-Topics/ Benefits/Prescription-Drugs/Downloads/StateUtilizationDataSpecifications. pdf. Accessed August 25, 2012.

18. Samuelson WF, Marks SG. Managerial Economics, 7th ed. Hoboken, NJ Wiley; 2012.

19. U.S. Department of Justice and the Federal Trade Commission. 1997 merger guidelines. Available at: http://www.justice.gov/atr/hmerger/11251. htm. Accessed August 25, 2012

20. U.S. Department of Justice and the Federal Trade Commission. Horizontal merger guidelines. August 19, 2010. Available at: http://www.justice.gov/atr/public/guidelines/hmg-2010.html. Accessed August 25, 2012

21. SDI Health LLC. 2010 top 200 generic drugs by total prescriptions: various years. Available at: http://drugtopics.modernmedicine.com/ Pharmacy+Facts+\&+Figures. Accessed August 25, 2012

22. Centers for Medicare \& Medicaid Services. Medicaid covered outpatient prescription drug reimbursement information by state: quarter ending March 2012. Available at: http://www.medicaid.gov/Medicaid-CHIPProgram-Information/By-Topics/Benefits/Prescription-Drugs/Downloads/ StateReimbChart2Q2012.pdf. Accessed August 25, 2012.

23. Briesacher BA, Soumerai SB, Field TS, Fouayzi H, Gurwitz JH. Nursing home residents and enrollment in Medicare Part D. J Am Geriatr Soc. 2009;57(10):1902-07.

24. Fick DM, Cooper JW, Wade WE, Waller JL, Maclean JR, Beers MH. Updating the Beers Criteria for potentially inappropriate medication use in older adults: results of a U.S. consensus panel of experts. Arch Intern Med. 2003;163(22):2716-24

25. Glass J, Lanctôt KL, Herrmann N, Sproule BA, Busto UE. Sedative hypnotics in older people with insomnia: meta-analysis of risks and benefits. BMJ. 2005;331(7526):1169-73.
26. Dusing ML, Guo JJ, Kelton CML, Pasquale MK. Competition and price discounts for a hospital buyer in the anti-infective pharmaceutical market. J Pharm Fin Econ Pol. 2005;14(2):59-85.

27. Frank RG, Salkever DS. Generic entry and the pricing of pharmaceuticals. J Econ Mgmt Strategy. 1997;6(1):75-90.

28. Reiffen D, Ward MR, Generic drug industry dynamics. Rev Econ Stat. 2005;87(1):37-49.

29. Caves RE, Whinston MD, Hurwitz MA. Patent expiration, entry, and competition in the U.S. pharmaceutical industry. Brookings Papers: Microeconomics. 1991;1991:1-66.

30. Rhoades SA, Cleaver JM. The nature of the concentration-price cost margin relationship for 352 manufacturing industries: 1967. S Econ J. 1973:40(1):90-102.

31. White LJ. Searching for the critical concentration ratio: an application of the "switching of regimes" technique. In: Goldfeld S, Quandt R, eds., Studies in Nonlinear Estimation. Cambridge, MA: Ballinger; 1976:61-76.

32. Geithman FE, Marvel HP, Weiss LW. Concentration, price, and critical concentration ratios. Rev Econ Stat. 1981;63(3):346-53.

33. Azzam AM, Rosenbaum DI, Weliwita A. Is there more than one critical concentration ratio? An empirical test for the Portland cement industry. App Econ. 1996;28:673-78.

34. Korn LM, Reichert S, Simon T, Halm EA. Improving physicians' knowledge of the costs of common medications and willingness to consider costs when prescribing. J Gen Intern Med. 2003;18(1):31-37.

35. Reissman D. Prior authorization: what does it really cost? Health Care News. December 1, 2001. Available at: http://www.heartland.org/healthpolicy-news.org/article/421/Prior_Authorization_What_Does_it_Really_Cost. html. Accessed August 25, 2012.

36. National Health Policy Forum. The Medicaid drug rebate program. April 13, 2009. Available at: http://www.nhpf.org/library/the-basics/Basics_ MedicaidDrugRebate_04-13-09.pdf. Accessed August 25, 2012.

37. Bergman D, Kaye N, Hoadley J, Crowley J. State experience in creating effective P\&T committees. National Academy for State Health Policy. March 2006. Available at: http://www.nashp.org/sites/default/files/medicaid_pandt. pdf. Accessed August 25, 2012.

38. Kaiser Commission on Medicaid and the Uninsured. Medicaid and managed care. December 2001. Available at: http://www.kff.org/Medicaid/upload/ Medicaid-and-Managed-Care-Fact-Sheet.pdf. Accessed August 25, 2012.

39. Gifford K, Smith VK, Snipes D, Paradise J. A profile of Medicaid managed care programs in 2010: findings from a 50-state survey. Kaiser Commission on Medicaid and the Uninsured. September 2011. Available at: http://www. kff.org/medicaid/upload/8220-ES.pdf. Accessed August 25, 2012. 